\title{
The Multi-Dimensional Blood/Injury Phobia Inventory: Its psychometric properties and relationship with disgust propensity and disgust sensitivity
}

Citation for published version (APA):

van Overveld, M., de Jong, P. J., \& Peters, M. L. (2011). The Multi-Dimensional Blood/Injury Phobia Inventory: Its psychometric properties and relationship with disgust propensity and disgust sensitivity. Journal of Anxiety Disorders, 25(3), 319-325. https://doi.org/10.1016/j.janxdis.2010.10.004

Document status and date:

Published: 01/01/2011

DOI:

10.1016/j.janxdis.2010.10.004

Document Version:

Publisher's PDF, also known as Version of record

Document license:

Taverne

Please check the document version of this publication:

- A submitted manuscript is the version of the article upon submission and before peer-review. There can be important differences between the submitted version and the official published version of record.

People interested in the research are advised to contact the author for the final version of the publication, or visit the DOI to the publisher's website.

- The final author version and the galley proof are versions of the publication after peer review.

- The final published version features the final layout of the paper including the volume, issue and page numbers.

Link to publication

\footnotetext{
General rights rights.

- You may freely distribute the URL identifying the publication in the public portal. please follow below link for the End User Agreement:

www.umlib.nl/taverne-license

Take down policy

If you believe that this document breaches copyright please contact us at:

repository@maastrichtuniversity.nl

providing details and we will investigate your claim.
}

Copyright and moral rights for the publications made accessible in the public portal are retained by the authors and/or other copyright owners and it is a condition of accessing publications that users recognise and abide by the legal requirements associated with these

- Users may download and print one copy of any publication from the public portal for the purpose of private study or research.

- You may not further distribute the material or use it for any profit-making activity or commercial gain

If the publication is distributed under the terms of Article $25 \mathrm{fa}$ of the Dutch Copyright Act, indicated by the "Taverne" license above, 


\title{
The Multi-Dimensional Blood/Injury Phobia Inventory: Its psychometric properties and relationship with disgust propensity and disgust sensitivity
}

\author{
Mark van Overveld ${ }^{\mathrm{a}, *}$, Peter J. de Jong ${ }^{\mathrm{b}}$, Madelon L. Peters ${ }^{\mathrm{c}}$ \\ a Marketing Management, Erasmus University Rotterdam, P.O. Box 1738, 3000 DR Rotterdam, The Netherlands \\ ${ }^{\mathrm{b}}$ Department of Clinical and Developmental Psychology, University of Groningen, Grote Kruisstraat 2/1, 9712 TS Groningen, The Netherlands \\ ${ }^{\mathrm{c}}$ Department of Clinical Psychological Science, Maastricht University, P.O. Box 616, 6200 MD Maastricht, The Netherlands
}

\section{A R T I C L E I N F O}

\section{Article history:}

Received 17 December 2009

Received in revised form 16 October 2010

Accepted 19 October 2010

\section{Keywords:}

Disgust propensity

Disgust sensitivity

Scale development

Blood/injury phobia

Factor analysis

\begin{abstract}
A B S T R A C T
The Multi-Dimensional Blood Phobia Inventory (MBPI; Wenzel \& Holt, 2003) is the only instrument available that assesses both disgust and anxiety for blood-phobic stimuli. As inflated levels of disgust propensity (i.e., tendency to experience disgust more readily) are often observed in blood phobia, the MBPI appears a promising instrument for disgust research. First, we examined its psychometric properties. Next, it was examined whether disgust sensitivity (i.e., considering experiencing disgust as something horrid) had added predictive value compared to disgust propensity in blood phobia. Therefore, students and university employees $(N=616)$ completed the MBPI, indices on blood phobia, disgust propensity and sensitivity.

The MBPI proved to be reliable and valid. Further, it correlated moderately to high with disgust propensity and sensitivity. Additionally, disgust propensity and sensitivity were both significant predictors for blood phobia. In conclusion, the MBPI appears a valuable addition to the currently available arsenal of indices to investigate blood phobia.
\end{abstract}

(C) 2010 Elsevier Ltd. All rights reserved.

\section{Introduction}

Accumulating evidence suggests that the emotion of disgust may be crucially involved in the etiology of blood phobia (Page, 1994). For example, blood phobic participants appear to be characterized by inflated levels of disgust propensity (i.e., the tendency to experience the emotion of disgust more readily) (Olatunji, Sawchuk, de Jong, \& Lohr, 2006; Page, 1994, 2003; Schienle, Schäfer, Walter, Stark, \& Vaitl, 2005). Furthermore, in the presence of their phobic stimulus, blood phobic participants report to experience primarily disgust (Tolin, Lohr, Sawchuk, \& Lee, 1997). Additionally, disgust-specific facial EMG becomes activated in response to blood-injury related slides (Yartz \& Hawk, 2002). Lastly, a recent evaluation of Taylor's model on the hierarchical structure of fear (1998) indicated that in anxiety disorders, both trait anxiety and trait disgust contribute significantly to phobic complaints like blood phobia (McDonald, Hartman, \& Vrana, 2008).

Currently, various indices are available to index blood phobia. For example, the Multiple Fear Survey (MFS; Kleinknecht, 1991), the Mutilation Questionnaire (MQ; Kleinknecht \& Thorndike, 1990), the Blood-Injury Symptoms Scale (BISS; Page, Bennett, Carter, Smith, \& Woodmore, 1997), Injection Phobia Scale-Anxiety (IPS-

\footnotetext{
* Corresponding author. Tel.: +31 010 4081970; fax: +31 0104089011

E-mail address: MOverveld@RSM.nl (M. van Overveld).
}

Anx; Öst, Hellström, \& Käver, 1992), and the Blood-Injury Phobia Questionnaire (BIQ; de Jong \& Merckelbach, 1998). Although these questionnaires are reliable and valid indices to measure blood fear, none measures the full domain of possible stimuli and responses. For example, several of these indices appear very limited with respect to the number of blood-injury phobic stimuli that are investigated. Considering the potential role of the emotion of disgust in blood phobia, questionnaires should investigate both levels of fear and disgust associated with phobic stimuli. So far, only one questionnaire exists that examines both levels of fear and disgust in relation to a wide range of blood phobic stimuli, namely the MultiDimensional Blood-Injury Inventory (Wenzel \& Holt, 2003). The MBPI was proposed to assess five possible response types (disgust, fear, worry, avoidance, fainting) in the individual for four types of blood-injury stimuli (blood, injury, injections, hospitals), with both a self- and other-focus. The present study was designed to test psychometric properties of this promising instrument.

So far, only two studies were conducted using the MBPI. In a large sample of undergraduate students, factor analyses showed that six factors could be observed, that represented either stimulus domains or fainting. Thus, six subscales were formed: Injections, Hospitals, Injury, Blood-Self, Blood-Others, and Fainting (Wenzel \& Holt, 2003). In another study (Wenzel \& Sawchuk, 2004), this six-subscale version of the MBPI appeared a valid and internally consistent index. The MBPI subscales correlated meaningfully with indices of blood- and injection-fear (i.e., MQ MFS). 
Further, discriminant validity was adequate as the total score of the MBPI did not correlate with the unrelated condition of spider fear. Yet, it should immediately be acknowledged that the research sample in that particular study was relatively small $(N=45)$, thereby limiting generalizability of these findings. Therefore, the first aim of the present study was to replicate the previous psychometric evaluations and to investigate whether the previously published six-factor solution (Wenzel \& Holt, 2003) can be observed in an independent sample.

Furthermore, research already showed that inflated levels of disgust propensity (i.e., tendency to experience disgust more readily) are strongly associated with blood fear (de Jong \& Merckelbach, 1998; Page, 1994). More specifically, blood phobia has been associated with disgust propensity towards stimuli in the animalreminder disgust domain (A-R) (i.e., disgust for stimuli that remind people of their animal origin; see also Rozin, Haidt, \& McCauley, 2000). In addition to this, recent research provided preliminary evidence to suggest that elevated levels of disgust sensitivity (i.e., tendency to evaluate the experience of disgust negatively) are also associated with blood phobia (e.g., van Overveld, de Jong, Peters, Cavanagh, \& Davey, 2006). Thus, both types of trait disgust factors may be important in the aetiology of blood phobic symptoms. Since the relationship between disgust sensitivity and blood phobia has rarely been explored, a second aim of the present study was to test further whether disgust propensity and disgust sensitivity are independently associated with blood fear (BIQ MFS, IPS-Anx), and with the MBPI in particular. We expected that the MBPI would display at least similar correlations with indices on disgust propensity and sensitivity compared to the existing indices of blood fear. Moreover, it was expected that the interplay of both disgust traits would display strong associations with blood phobic symptomatology. In addition, we explored whether associations with the various disgust subtypes (core/A-R) are strongest for the A-R-type (cf. de Jong \& Merckelbach, 1998).

Finally, to control for the possibility that the predicted correlations between the MBPI and disgust propensity/sensitivity may be attributed to a generally heightened negative affect, a scale on Neuroticism was also administered.

\section{Methods}

\subsection{Participants}

For two consecutive years, a large sample of students and university employees $(N=616)$ was recruited at the faculties of Medicine, Health Sciences, and Psychology at Maastricht University. As women tend to be overrepresented in these faculties, both the research sample of the first ( $n=309 ; 68 \%$ women) and second study ( $n=307 ; 62.9 \%$ women) were characterized by a large proportion of women. Overall, participants had a mean age of 29 years ( $S D=11.0$; range $18-72$ years).

\subsection{Instruments}

\subsubsection{Multi-Dimensional Blood Phobia Inventory (MBPI; Wenzel $\mathcal{E}$ Holt, 2003)}

This 40-item index measures blood-injury phobia across four types of stimuli (blood, injury, injections, hospitals) and five response types (disgust, fear, worry, avoidance, fainting). Additionally, a self versus other focus is also obtained for all items. Thus, participants rate whether the items are typical for them on a scale from 1 (='very slightly or not at all') to 4 (='extremely'). Both a total sum score $(0-160)$ and the following subscales can be calculated: Injections (0-24), Hospitals (0-24), Fainting (0-24), Blood-Self $(0-16)$, Blood-Others $(0-16)$, and Injury (0-16). The
MBPI and its subscales have been shown to be internally consistent (Wenzel \& Sawchuk, 2004). A professional translator translated the English version into Dutch

\subsubsection{Medical Fear Survey (MFS; Kleinknecht, Kleinknecht,} Sawchuk, Lee, E Lohr, 1999)

This 50-item scale assesses participants' fear for a wide range of medical-related situations and procedures, such as blood draws, visiting a hospital, and seeing wounds. Participants indicate their degree of fear on a scale from 1 (='no fear or concern at all') to 5 (='terror'). A total score can be calculated (0-200) as well as five subscales: Injections, Sharp Objects, Examinations, Blood and Mutilation (each 0-40). All are internally consistent (all $\alpha$ 's > .78; Kleinknecht, Thorndike, \& Walls, 1996)

\subsubsection{Blood-Injury Phobia Questionnaire (BIQ; de Jong \&}

Merckelbach, 1998)

This questionnaire examines both fear and fainting history for various items. On the first 10 items, participants rate their fear for 10 blood phobic stimuli on a scale from 0 (='no fear') to 4 (='maximal fear'; range $=0-40)$. On the second part, participants indicate their fainting history for these items on a scale from 0 (='never') to 2 (='often'; range: 0-20). Internal consistency is satisfactory (all $\alpha$ 's > .73; Merckelbach, Muris, de Jong, \& de Jongh, 1999).

\subsubsection{Injection Phobia Scale-Anxiety (IPS-Anx; Öst et al., 1992)}

This questionnaire assesses fear of injections. On 18 items, participants indicate their anxiety on a scale from 0 (='no anxiety') to 4 (='maximum anxiety') if they were to have an injection and/or venipuncture. A total score can be obtained (0-72). The IPS-Anx appears internally consistent ( $\alpha=.89$; Olatunji, Smits, Connolly, Willems, \& Lohr, 2007a)

\subsubsection{Disgust Propensity and Sensitivity Scale-Revised (DPSS-R; van Overveld et al., 2006)}

This questionnaire measures both disgust propensity (i.e., how readily do participants experience disgust) and disgust sensitivity (i.e., how horrid do they consider experiencing disgust). Here, the shortened version was used which has recently been validated (Fergus \& Valentiner, 2009; van Overveld, de Jong, \& Peters, 2010). Participants rate frequency of experiencing various (bodily) symptoms, as well as their emotional impact on a scale from 1 (='never') to 5 (='always'). Both a total score (range: 12-60) and separate subscales for disgust propensity and disgust sensitivity can be obtained (both 6-30). The DPSS-R and its subscales are internally consistent (all $\alpha$ 's > .78; Fergus \& Valentiner, 2009)

\subsubsection{Disgust Scale-Revised (DS-R; Olatunji, Williams, et al., 2007)}

The original DS (Haidt, McCauley, \& Rozin, 1994) measures disgust propensity for 32 disgust elicitors. The DS consists of two parts. On the first part, participants rate whether a series of statements applies to them $(0=$ 'no', $1=$ 'yes'), while on the second part, participants rate how disgusted they would be when confronted with a series of stimuli $(0=$ 'not disgusting at all', $.5=$ 'slightly disgusting', 1 = 'very disgusting'). In accordance with recent recommendations (Olatunji, Smits, et al., 2007), only 25 items were used for the present analyses to calculate three subscales and a total score. In previous research (Olatunji, Williams, et al., 2007), internal consistency appeared good for the total score of the DS-R $(\alpha=.84)$ and satisfactory for three subscales measuring core disgust $(\alpha=.84)$, Animal-Reminder disgust $(\alpha=.78)$, and Contamination $(\alpha=.61)$ 
Table 1

Means, standard deviations, ranges, and scales (min.-max.) of all questionnaires.

\begin{tabular}{|c|c|c|c|c|}
\hline Questionnaires & Men & Women & Total group & Cronbach's alpha \\
\hline MBPI total & $19.74(20.73)$ & $19.06(20.65)$ & $19.48(20.72)$ & .96 \\
\hline Inject & $3.53(4.57)$ & $3.78(5.22)$ & $3.73(5.04)$ & .91 \\
\hline Hosp & $2.238(3.66)$ & $1.45(2.62)^{* *}$ & $1.77(3.04)$ & .86 \\
\hline Faint & $1.31(3.02)$ & $1.34(3.02)$ & $1.34(3.01)$ & .90 \\
\hline Bl-S & $1.40(2.51)$ & $1.50(2.88)$ & $1.48(2.78)$ & .90 \\
\hline Injury & $3.97(3.14)$ & $3.67(3.15)$ & $3.80(3.15)$ & .74 \\
\hline Bl-O & $2.20(2.91)$ & $2.48(2.90)$ & $2.43(2.94)$ & .81 \\
\hline MFS total & $24.97(18.83)$ & $32.58(21.11)^{* *}$ & $30.15(20.73)$ & .95 \\
\hline Inj & $4.68(5.38)$ & $5.88(6.25)^{*}$ & $5.52(6.00)$ & .91 \\
\hline ShO & $4.06(3.99)$ & $6.00(4.98)^{* *}$ & $5.38(4.78)$ & .88 \\
\hline Ex & $6.48(4.48)$ & $7.52(4.59)^{* *}$ & $7.18(4.57)$ & .85 \\
\hline $\mathrm{Bl}$ & $1.95(3.87)$ & $2.70(4.71)^{*}$ & $2.48(4.46)$ & .92 \\
\hline Mut & $7.80(6.03)$ & $10.48(6.83)^{* *}$ & $9.59(6.68)$ & .90 \\
\hline BIQ-Fear & $15.77(5.32)$ & $17.91(5.63)^{* *}$ & $16.75(5.57)$ & .85 \\
\hline BIQ-Faint & $10.42(1.68)$ & $10.46(1.33)$ & $10.45(1.45)$ & .84 \\
\hline IPS-Anx & $20.11(5.70)$ & $21.58(6.86)$ & $21.10(6.47)$ & .94 \\
\hline DPSS-RP & $13.80(3.64)$ & $15.46(3.65)^{* *}$ & $14.90(3.71)$ & .80 \\
\hline DPSS-RS & $9.76(3.06)$ & $10.31(3.34)^{*}$ & $10.11(3.25)$ & .76 \\
\hline DS-R total & $10.06(3.38)$ & $12.53(3.01)^{* *}$ & $11.69(3.34)$ & .77 \\
\hline Core & $5.02(1.88)$ & $6.02(1.62)^{* *}$ & $5.68(1.77)$ & .62 \\
\hline AR & $2.70(1.24)$ & $3.58(1.34)^{* *}$ & $3.28(1.37)$ & .40 \\
\hline Cont & $2.33(1.01)$ & $2.92(.89)^{* *}$ & $2.73(.98)$ & .52 \\
\hline SCL-90-Ag & $7.84(2.36)$ & $7.93(2.28)$ & $7.91(2.34)$ & .85 \\
\hline SCL-90-Dep & $21.60(6.93)$ & $22.95(7.82)^{*}$ & $22.55(7.77)$ & .92 \\
\hline EPQ-N & $2.97(2.73)$ & $4.40(3.09)^{* *}$ & $3.92(3.03)$ & .81 \\
\hline Valid $N$ & 208 & 403 & & \\
\hline
\end{tabular}

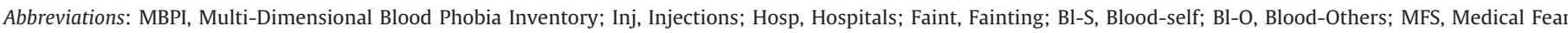

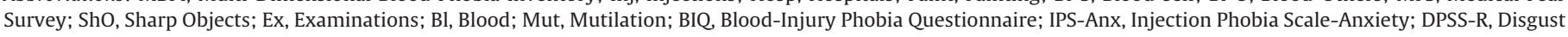

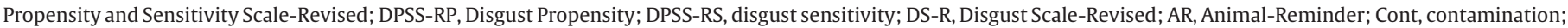
SCL-90, Symptoms Check List; Ag, Agoraphobia; Dep, Depression; EPQ-N, Eysenck Personality Questionnaire-Neuroticism.

Standard deviations are described in parentheses.

${ }^{*} p<.05$.

$p<.01$.

\subsubsection{Eysenck Personality Questionnaire Neuroticism (EPQ-N;} Eysenck E' Eysenck, 1991)

This subscale of the EPQ measures neuroticism. It consists of 12 items where participants rate on a dichotomous scoring format $(0=$ 'no', 1 = 'yes') whether a series of statements regarding their personality is typical of them. Its psychometric qualities are wellestablished, and it has shown to be a valid and reliable index for neuroticism (e.g., $\alpha=.73$; Alexopoulos \& Kalaitzidis, 2004).

\subsubsection{Symptom Checklist-90 (SCL-90; Derogatis, Lipman, \& Covi, 1973)}

The 90-item SCL-90 measures general symptoms of psychopathology. Participants rate whether they experience various physiological and psychological complaints on a scale from 1 (="not at all') to 5 (='very much'). Although several subscales for psychopathology can be calculated, only those for agoraphobia (range 7-35) and depression (16-80) were used in this study. The SCL-90 demonstrated high internal consistency in previous studies (e.g., $\alpha>$.80; Hendriks, 1990).

\subsection{Procedure}

Via posters in the University buildings and advertisements in the university paper, participants were invited to contact the researchers if they wished to participate. The posters and advertisements indicated that the study would last approximately an hour and questionnaires would address a variety of topics, such as personality, emotions, and attitudes. Following this, participants were given a package of questionnaires. The distribution order was randomized and fixed for all questionnaires and was as follows for the questionnaires in the present study: EPQ-N, SCL-90, MFS, DS-R, MBPI, DPSS-R, BIQ. The package contained a few additional questionnaires (e.g., on self-esteem and happiness) for the purpose of another study. During the second data collection period, the IPS-Anx was added. Participants could complete the questionnaires either privately at home or in the conference room of the department. Further, participants were told that a substantial financial incentive (50 euro) would be distributed via a lottery to 10 people who fully completed all questionnaires. To examine test-retest reliability, 40 participants of the first study were asked to complete the MBPI again after six to eight weeks.

\section{Results}

\subsection{Data reduction and analysis}

First, the data from the two studies was pooled into one sample. Then, in accordance with suggestions by Schafer and Graham (2002), missing values were estimated with regression analyses using the Statistical Package for Social Sciences (SPSS 12.0.1) unless $>10 \%$ missing values were observed on a single questionnaire. The MBPI was obtained from all participants, the DS-R and the DPSS-R were missing for one person, and the MFS and the EPQ$\mathrm{N}$ were missing for two persons. Five persons did not report their gender. After investigating the general statistics for the entire research population, a confirmatory factor analysis tested whether the previously suggested MBPI distribution (see also Wenzel \& Holt, 2003) fitted the data well. Then, test-retest reliability was examined for the MPBI using the Intra-Class Correlation Coefficient (ICC) $(n=40)$. To establish divergent and convergent validity, bivariate correlations between the MBPI and other indices for blood fear (BIQ, MFS, IPQ-Anx) were investigated $(N=616)$. To check whether the MBPI is specific to blood phobia, bivariate correlations were calculated between the MBPI and two subscales on the SCL-90 that index symptoms of two disgust-unrelated 
Table 2

Lambda factor loadings of the CFA of all MBPI-items.

\begin{tabular}{|c|c|c|c|c|c|c|}
\hline Factor loadings for each item & Inj & Hosp & Faint & Bl-S & Injury & $\mathrm{Bl}-\mathrm{O}$ \\
\hline 7 & .80 & & & & & \\
\hline 9 & .79 & & & & & \\
\hline 14 & .83 & & & & & \\
\hline 28 & .78 & & & & & \\
\hline 35 & .84 & & & & & \\
\hline 38 & .79 & & & & & \\
\hline 11 & & .69 & & & & \\
\hline 13 & & .55 & & & & \\
\hline 17 & & .80 & & & & \\
\hline 22 & & .80 & & & & \\
\hline 25 & & .85 & & & & \\
\hline 27 & & .85 & & & & \\
\hline 3 & & & .67 & & & \\
\hline 10 & & & .72 & & & \\
\hline 15 & & & .85 & & & \\
\hline 20 & & & .86 & & & \\
\hline 21 & & & .76 & & & \\
\hline 39 & & & .76 & & & \\
\hline 1 & & & & .83 & & \\
\hline 16 & & & & .82 & & \\
\hline 30 & & & & .84 & & \\
\hline 40 & & & & & .88 & \\
\hline 6 & & & & & .58 & \\
\hline 18 & & & & & .77 & \\
\hline 31 & & & & & .68 & \\
\hline 36 & & & & & .83 & \\
\hline 5 & & & & & & .57 \\
\hline 6 & & & & & & .70 \\
\hline 24 & & & & & & .91 \\
\hline 26 & & & & & & .79 \\
\hline Valid $N$ & & & & & & 616 \\
\hline
\end{tabular}

Abbreviations: MBPI, Multi-Dimensional Blood Phobia Inventory, Inj, injections, Hosp, Hospitals, Faint, Fainting, Bl-S, Blood-self, Bl-O, Blood-O.

clinical conditions, namely agoraphobia and depression $(N=614)$. Next, to determine whether trait disgust (particularly propensity for A-R disgust) is associated with fear of blood, bivariate correlations were calculated between the MBPI and indices measuring general disgust propensity (DPSS-RP, DS-R, DQ) and disgust sensitivity (DPSS-RS) $(N=616)$. To determine whether specifically disgust propensity for A-R disgust is associated with blood fear (as indexed by the MBPI), stepped blocked entry regression analyses were performed in which the three DS-subscales AR-disgust, core-disgust and contamination were included as predictors in the first step. In the second step, neuroticism (EPQ-N) was added to examine whether associations between disgust propensity and blood fear are independent of neuroticism. Finally, to determine the relative strength of disgust propensity and disgust sensitivity in predicting blood phobia, another regression analysis was performed $(N=616)$ with blood phobia (indexed by MBPI) as the dependent variable and disgust propensity, disgust sensitivity, and their interaction as predictor variables. Again, this analysis controlled for the potential influence of neuroticism.

\subsection{Descriptive statistics}

Table 1 presents the means and standard deviations for all questionnaires. A series of post hoc $t$-tests revealed that men scored significantly higher than women on the Hospital scale of the MBPI $(p<.01)$, while scores on the other scales of the MBPI did not differ between men and women. Women did score significantly higher on the BIQ, MFS (all $p$ 's $<.05$ ) and a trend was observed for IPS-Anx $(t(300)=-1.89 ; p=.06)$. Further, women scored significantly higher than men on disgust propensity (both DPSS and DS), disgust sensitivity, depression, and neuroticism (all $p$ 's $<.05$ ). No gender differences were observed for agoraphobia.

\subsection{Confirmatory factor analyses}

Using PRELIS, poly-choric correlation matrices were obtained. Next, using the Weighted Least-Squares estimation, a confirmatory factor analyses was conducted in LISREL 8.54 (Jöreskog \& Sörbom, 2002). Since earlier research already investigated which latent factors were present, we only investigated whether the six-factor distribution fitted the data well. Latent variables were allowed to correlate while item residuals were only allowed to correlate if the items were in the same subscale. Items were only allowed to be on one subscale.

In accordance with recommendations by Hu and Bentler (1999), both absolute and incremental fit indices were used to examine model fit. Both are equally important in assessing model fit. The chi-square test $\left(\chi^{2} / \mathrm{df}\right)$ is the most widely used absolute fit index and is generally considered good with a ratio below 3 . Here, the ratio is $4.5\left(\chi^{2}=1769.84 ; \mathrm{df}=387\right)$, suggesting that the model did not display good fit. For incremental fit indices, the criteria as recommended by Hu and Bentler (1999) were used: Comparative Fit Index $(\mathrm{CFI}) \geq .90$; Tucker Lewis Index $(\mathrm{TLI})>.95$; Standardized Root Mean Square Residual $(S R M R) \leq .06$. Although the model did not fit optimally for the absolute fit indices, the model did pass all criteria for incremental indices $(\mathrm{CFI}=.97 ; \mathrm{TLI}=.96$; $\mathrm{SRMR}=.06)$, indicating that the current MBPI factor distribution has an acceptable model fit and fits the data. Table 2 presents the lambda factor loadings of all items for the final model.

\subsection{Reliability}

Table 1 shows that the MBPI and its subscales appear internally consistent. Additionally, the intra-class correlation coefficient showed that test-retest reliability was excellent for the total score of the MBPI $(\alpha=.96)$ and its subscales (all $\alpha$ 's $>.90)$ after a six to eight weeks follow-up period. 
Table 3

Bivariate correlations between the MBPI and blood fear measures (MFS, BIQ, IPS-Anx), trait disgust (DPSS-R, DS-R), psychopathology (SCL-90), and neuroticism (EPQ-N),

\begin{tabular}{|c|c|c|c|c|c|c|c|}
\hline Index & MBPI total & Inj & Hosp & Faint & Bl-S & Injury & $\mathrm{Bl}-\mathrm{O}$ \\
\hline MFS total & .67 & .60 & .45 & .50 & .53 & .47 & .60 \\
\hline In & .70 & .80 & .38 & .54 & .58 & .38 & .56 \\
\hline Sho & .40 & .28 & .26 & .28 & .28 & .36 & .38 \\
\hline Ex & .39 & .31 & .39 & .20 & .23 & .36 & .28 \\
\hline $\mathrm{Bl}$ & .66 & .56 & .40 & .60 & .63 & .41 & .60 \\
\hline Mut & .47 & .37 & .32 & .33 & .34 & .33 & .50 \\
\hline BIQ-Fear & .73 & .68 & .49 & .49 & .57 & .51 & .65 \\
\hline BIQ-Faint & .36 & .27 & .24 & .59 & .29 & .13 & .31 \\
\hline IPS-Anx & .59 & .73 & .38 & .48 & .49 & .30 & .39 \\
\hline $\mathrm{Ag}$ & .22 & .17 & .16 & .25 & .18 & .12 & .19 \\
\hline Dep & .23 & .16 & .18 & .19 & .14 & .18 & .20 \\
\hline DPSS-RP & .39 & .31 & .23 & .24 & .30 & .34 & .37 \\
\hline DPSS-RS & .44 & .31 & .37 & .30 & .33 & .35 & .35 \\
\hline DS-R total & .27 & .22 & .15 & .17 & .14 & .25 & .27 \\
\hline Core & .22 & .18 & .14 & .13 & .11 & .22 & .21 \\
\hline $\mathrm{AR}$ & .20 & .18 & .11 & .13 & .08 & .17 & .21 \\
\hline Cont & .30 & .26 & .10 & .20 & .24 & .26 & .34 \\
\hline EPQ-N & .22 & .16 & .15 & .12 & .15 & .18 & .20 \\
\hline Valid $N$ & & & & & & & 616 \\
\hline
\end{tabular}

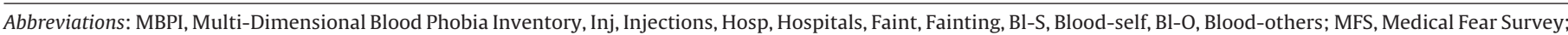

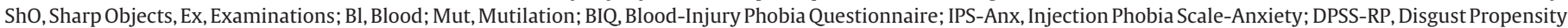

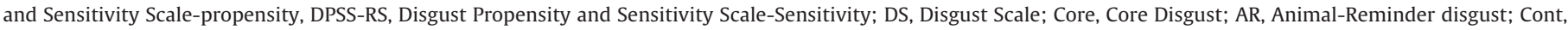
Contamination, SCL-90, Symptoms Check List; Ag, Agoraphobia, Dep, Depression; EPQ-N, Eysenck Personality Questionnaire-Neuroticism.

Standard deviations are described in parentheses. Predicted convergent correlations of the MBPI are highlighted in bold. All correlations $>.10$ were significant with $p<.01$

\subsection{Construct validity of the MBPI}

As can be seen in Table 3, the MBPI and its subscales correlated moderately to high with other indices of blood fear (BIQ MFS, IPSAnx). Moreover, adding to its validity, the Injection subscale of the MBPI correlated highest with the IPS-Anx $(r=.73)$ and the injection scale of the MFS. Further, the Fainting subscale of the MBPI correlated high with BIQ-Faint (both measure blood-related fainting) while all other MBPI subscales correlated only moderately with BIQ-Faint. Additionally, MBPI scales related to blood stimuli correlated highest with MFS-Blood, while MBPI-Hospitals correlated high ( $r$ 's .38-.40) with various MFS-scales, including MFS-Medical Examinations. Thus, the MPBI correlates meaningfully with other indices of blood phobia measuring similar concepts. Finally, correlations between the MPBI and agoraphobia and depression are low, indicating that the MBPI is a sensitive as well as a specific index for measuring blood fearful symptoms.

\subsection{The relation between $M B P I$ and ( $A-R)$ disgust propensity}

As indicated in Table 3, the MBPI showed moderate correlations with both disgust propensity (DS-R, DPSS-RP) and disgust sensitivity (DPSS-RS). To determine the relative strength of disgust propensity for A-R disgust in relation to the other disgust domains as predictor of blood fear, regression analyses using a blocked entry model were conducted (Method = Enter). In the first step, the three DS-R subscales (DS-R core, DS-R AR, DS-R contamination) were included as independent variables and MBPI total score as dependent variable. In the second step, neuroticism (EPQ-N) was added to the predictors to control for neuroticism. Initially, DS-R AR $(\beta=.09$; $t=1.99 ; p=.04)$ and DS-R Contamination $(\beta=.22 ; t=4.74 ; p<.01)$ proved significant. In the second step, DS-R contamination $(\beta=.19$; $t=4.17 ; p<.01)$ remained a significant predictor while DS-R AR $(\beta=.09 ; t=1.88 ; p=.06)$ demonstrated a trend, as can be seen in a summary of the final model in Table 4 . Thus, both DS-R AR and DS-R contamination were associated with blood fear as indexed by the MBPI, and these associations were independent of neuroticism.

\subsection{Contribution of disgust sensitivity to fear of blood}

To determine the relative strength of disgust propensity and sensitivity as predictors of blood phobia (MPBI-total), regression analyses using a blocked entry model were conducted. Disgust propensity (DPSS-RP) was added in the first step, disgust sensitivity (DPSS-RS) in the second step, and their interaction in the final step. Independent variables were first centered. The interaction

Table 4

Hierarchical regression analyses for domain-specific disgust propensity (DS-R) and general disgust propensity/sensitivity (DPSS-R) as predictors of the MBPI total score.

\begin{tabular}{|c|c|c|c|c|c|}
\hline & & $B$ & SE B & $\beta$ & $p$ \\
\hline \multirow[t]{5}{*}{ MBPI } & $R^{2}=.11$ for & & & & \\
\hline & DS-R-Core & .26 & .57 & .02 & .65 \\
\hline & DS-R-AR & 1.28 & .68 & .09 & .06 \\
\hline & DS-R-Cont & 4.05 & .97 & .19 & $<.01$ \\
\hline & EPQ-N & 1.04 & .28 & .15 & $<.01$ \\
\hline \multirow[t]{4}{*}{ MBPI } & $R^{2}=.24$ for & & & & \\
\hline & DPSS-RP & 1.27 & .23 & .23 & $<.01$ \\
\hline & DPSS-RS & 1.99 & .27 & .31 & $<.01$ \\
\hline & EPQ-N & .25 & .26 & .04 & .34 \\
\hline
\end{tabular}


term indicates whether especially the interplay between disgust propensity and sensitivity is important for blood fear. However, the interaction term did not reach significance and was subsequently removed from the analyses.

Next, neuroticism (EPQ-N) was included to investigate whether disgust propensity and disgust sensitivity contribute independently from neuroticism to blood fear. Table 4 shows the final model. Both disgust propensity $(\beta=.23 ; t=5.51 ; p<.01)$ and sensitivity $(\beta=.31 ; t=7.53 ; p<.01)$ remained significant predictors of blood fear after controlling for neuroticism.

\section{Discussion}

The main findings were: (a) the six-factor distribution proposed by Wenzel and Holt (2003) had a satisfactory fit, (b) internal consistency and test-retest reliability were good for the total MBPI and its subscales, (c) the MBPI appears a valid indicator of blood fear as shown by the moderate to high correlations with other instruments measuring blood fear and low correlations with instruments measuring unrelated conditions (agoraphobia and depression), (d) blood phobia (indexed by MBPI) was associated with fear of contamination and AR-disgust, but not core disgust, (e) disgust sensitivity appeared of added value to disgust propensity in explaining variance on scores of blood phobia.

The MBPI was constructed to measure a broad range of feared stimuli and possible reactions to blood phobia-related stimuli. The present study confirmed that the MBPI contains six subscales representing various stimulus domains and a fainting subscale (Wenzel \& Holt, 2003). It should be noted that model fit was less adequate for the absolute fit index compared to the incremental fit indices. Yet, previous research also observed serious drawbacks with the routinely reported (absolute) chi-square test (e.g., Tanaka, 1993), so it is recommended to investigate model fit using several indicators. Taking the various indices into account, model fit is at least acceptable.

Further, in line with earlier work (Wenzel \& Holt, 2003; Wenzel \& Sawchuk, 2004), the MBPI demonstrated high internal consistency for both the total scale and the subscales. Test-retest reliability with an interval of six to eight weeks was excellent. Supporting previous research (Wenzel \& Holt, 2003; Wenzel \& Sawchuk, 2004), the MBPI correlated moderately to high with established scales on blood phobia (BIQ, MFS) or injection fear (IPS-Anx). Moreover, stimuli-specific MBPI-subscales correlated meaningfully with other stimuli-specific indices. For example, injection phobia scales (IPS-Anx) correlated best with MBPI Injection, and the Fainting subscale of the MBPI correlated highest with the Fainting-scale of the BIQ. Extending previous reports that the MBPI is not merely indexing general anxiety or distress (Wenzel \& Holt, 2003), in the present study, the MBPI correlated low with neuroticism (EPQ-N). This suggests that the MBPI measures specifically blood phobic complaints.

In accordance with previous studies (de Jong \& Merckelbach, 1998; Page, 1994, 2003; van Overveld et al., 2006), blood phobia was associated with heightened disgust propensity. Previous research showed that a propensity for A-R disgust may be particularly important in blood phobia while core disgust would be relatively less strongly associated with blood phobia (e.g., de Jong \& Merckelbach, 1998). In line with this, regression analyses revealed that the association between blood fear (as indexed by MBPI) and AR-disgust (as indexed by DS-R) demonstrated a trend while a significant association with DS-R Core disgust was absent. Interestingly, DS-R contamination proved the strongest predictor for blood fear. This supports a disease-avoidance interpretation of anxiety disorders (i.e., Matchett \& Davey, 1991), suggesting that the role of disgust in psychopathology may be to shield individu- als from contamination with hazardous pathogens (van Overveld, de Jong, \& Peters, 2009). Blood may present a powerful contaminating substance. Various diseases are transferred via contact with blood, rendering the threat of becoming contaminated very realistic. Previously, Olatunji, Smits, et al. (2007) reported that DSContamination was among the strongest predictors of obsessive compulsive symptoms, in contrast to DS-A-R which was unrelated to these symptoms. So, both contamination fear and trait disgust (e.g., AR-disgust) appear associated with specific disorders.

Yet, an alternative explanation may be that the items measuring DS-R Contamination reflect a quality that characterizes all disgusting items, the potency to contaminate other objects (see also Rozin, Millman, \& Nemeroff, 1986). Additionally, the contamination-subscale uses various A-R-related stimuli (e.g., feces, sex). Moreover, differential associations should be interpreted with caution, as the internal consistency of the DS-R subscales is rather low (e.g., $\alpha=.43$ for A-R). Nevertheless, the associations between the MBPI and the disgust propensity indices (DS-R, DPSS-R) underline the importance for clinical practice to consider (A-R) disgust-related avoidance behavior in diagnosis and treatment of blood phobia. In this respect, the MBPI may be valuable since it is the only instrument to investigate the role of disgust in response to blood-phobic stimuli.

In line with earlier work (van Overveld et al., 2006), both disgust propensity (DS-R, DPSS-RP) and disgust sensitivity (DPSS-RS) were independently associated with blood phobia. The prediction that especially the interplay between these disgust traits would be of critical importance was not confirmed.

Future research should take several issues into account. First, the sample consisted solely of undergraduate students and university employees. Thus, a logical next step would be to administer the MBPI in clinical settings to determine whether similar findings are obtained with a treatment-seeking sample and investigate whether the MBPI can accurately distinguish between high and low fearful individuals. Second, the present study incorporated students from the schools of Health Sciences, Psychology, and Medicine. It is likely that such students are interested in health-related topics and human physiology. Thus, the possibility arises that participants demonstrate relatively low levels of blood fear. This could artificially reduce the variance in scores on all blood phobia-scales. Although the MBPI displayed good convergent and discriminant validity, generalizability to the general population may be limited.

In summary, the MBPI appears to be a reliable and valid index to measure blood phobic symptoms. Not only is the MBPI an elaborate index to assess the full range of possible blood-phobia related stimuli, it is the only instrument available that includes disgust as a response type. In line with accumulating evidence that disgustrelated preoccupations are involved in blood phobia (e.g., de Jong \& Merckelbach, 1998; Page, 1994), the MBPI showed correlations with disgust propensity and sensitivity. Thus, the MBPI appears a valuable addition to the arsenal of current indices that may be used in clinical practice.

\section{Acknowledgements}

The authors express their gratitude to Ilona Winkelhorst and Ernst Claasen for their efforts in the process of data collection, and Erik Schouten for his statistical advice.

\section{References}

Alexopoulos, D. S., \& Kalaitzidis, I. (2004). Psychometric properties of Eysenck Personality Questionnaire-Revised (EPQ-R) short scale in Greece. Personality and Individual Differences, 37, 1205-1220.

Derogatis, L. R., Lipman, R. S., \& Covi, L. (1973). The SCL-90: an outpatient psychiatric rating scale. Psychopharmacology Bulletin, 19, 13-28. 
de Jong, P., \& Merckelbach, H. (1998). Blood-injection-injury phobia and fear of spiders: domain specific individual differences in disgust sensitivity. Personality and Individual Differences, 24, 153-158.

Eysenck, H. J., \& Eysenck, S. B. G. (1991). Manual of the Eysenck personality scales. London: Hodder \& Stoughton.

Fergus, T. A., \& Valentiner, D. P. (2009). The disgust propensity and sensitivity scalerevised: an examination of a reduced-item version. Journal of Anxiety Disorders, $23,703-710$

Haidt, J., McCauley, C., \& Rozin, P. (1994). Individual differences in sensitivity to disgust: a scale sampling seven domains of disgust elicitors. Personality and Individual Differences, 16, 701-713.

Hendriks, V. M. (1990). Psychiatric disorders in a Dutch addict population: rates and correlates of DSM-III diagnosis. Journal of Consulting and Clinical Psychology, 58, $158-165$.

Hu, L.-T., \& Bentler, P. M. (1999). Cut-off criteria for fit indexes in covariance structure analysis: conventional criteria versus new alternatives. Structural Equation Modeling, 6, 1-55.

Jöreskog, K. G., \& Sörbom, D. (2002). LISREL 8.54. Chicago, Scientific Software International, Inc.

Kleinknecht, R. A. (1991). Dimensions of blood/injury and medically related fears: development of the Medical Fears Survey. Paper presented to the 25th Annual Meeting of the Association for Advancement of Behavior Therapy, New York.

Kleinknecht, R. A., Kleinknecht, E. E., Sawchuk, C. N., Lee, T. C., \& Lohr, J. (1999). The Medical Fear Survey: psychometric properties. The Behavior Therapist, 22, 109-119.

Kleinknecht, R. A., \& Thorndike, R. M. (1990). The mutilation questionnaire as a predictor of blood/injury fear and fainting. Behaviour Research and Therapy, 28, $429-437$.

Kleinknecht, R. A., Thorndike, R. M., \& Walls, M. M. (1996). Factorial dimensions and correlates of blood, injury, injection and related medical fears: cross-validation of the Medical Fear Survey. Behaviour Research and Therapy, 34, 323-331.

Matchett, G., \& Davey, G. C. L. (1991). A test of disease-avoidance model of animal phobias. Behaviour Research and Therapy, 29, 91-94.

McDonald, S. D., Hartman, N. S., \& Vrana, S. R.(2008). Trait anxiety, disgust sensitivity, and the hierarchic structure of fears. Journal of Anxiety Disorders, 22, 1059-1074.

Merckelbach, H., Muris, P., de Jong, P. J., \& de Jongh, A. (1999). Disgust sensitivity, blood-injection-injury fear, and dental anxiety. Clinical Psychology and Psychotherapy, 6, 279-285.

Olatunji, B. O., Sawchuk, C. N., de Jong, P. J., \& Lohr, J. M. (2006). The structural relation between disgust sensitivity and blood-injection-injury fears: a cross-cultural comparison of U.S. and Dutch data. Journal of Behavior Therapy and Experimental Psychiatry, 37, 16-29.

Olatunji, B. O., Smits, J. A., Connolly, K. M., Willems, J., \& Lohr, J. M. (2007). Examination of the rate of decline in fear and disgust during exposure to threatrelevant stimuli in blood-injection-injury phobia. Journal of Anxiety Disorders, $21,445-455$.
Olatunji, B. O., Williams, N. L., Tolin, D. F., Sawchuk, C. N., Abramowitz, J. S., Lohr, J. M., \& Elwood, L. (2007). The disgust scale: item analysis, factor structure, and suggestions for refinement. Psychological Assessment, 19, 281-297.

Öst, L.-G., Hellström, K., \& Käver, A. (1992). One versus five sessions of exposure in the treatment of injection phobia. Behavior Therapy, 23, 263-282.

Page, A. C., Bennett, K. S., Carter, O., Smith, J., \& Woodmore, K. (1997). The bloodinjection symptom scale (BISS): assessing a structure of phobic symptoms elicited by blood and injections. Behaviour Research and Therapy, 35, 457-464.

Page, A. C. (1994). Blood-injury phobia. Clinical Psychology Review, 14, 443-461.

Page, A. C. (2003). The role of faintness elicited by blood and injection stimuli.Journal of Anxiety Disorders, 17, 45-58.

Rozin, P., Haidt, J., \& McCauley, C. R. (2000). Disgust. In: M. Lewis, \& J. M. Haviland Jones (Eds.), Handbook of Emotions (2nd ed., pp. 637-652). New York: Guilford Press.

Rozin, P., Millman, L., \& Nemeroff, C. (1986). Operations of the laws of sympathetic magic in disgust and other domains. Journal of Personality and Social Psychology, $50,703-712$.

Schafer, J. L., \& Graham, J. W. (2002). Missing data: our view of the state of the art. Psychological Methods, 7, 147-177.

Schienle, A., Schäfer, A., Walter, B., Stark, R., \& Vaitl, D. (2005). Elevated disgust sensitivity in blood phobia. Cognition and Emotion, 19, 1229-1241.

Tanaka, J. S. (1993). Multifaceted conceptions offit in structure equation models. In: K. A. Bollen, \& J. S. Long (Eds.), Testing structural equation models. Newbury Park, CA: Sage.

Taylor, S. (1998). The hierarchic structure of fears. Behaviour Research and Therapy, 36, 205-214.

Tolin, D. F., Lohr, J. M., Sawchuk, C. N., \& Lee, T. C. (1997). Disgust and disgust sensitivity in blood-injection-injury and spider phobia. Behaviour Research and Therapy, 35, 949-953.

van Overveld, W. J. M., de Jong, P. J., Peters, M. L., Cavanagh, K., \& Davey, G. C. L. (2006). Disgust propensity and disgust sensitivity: separate constructs that are differentially related to specific fears. Personality and Individual Differences, 41, 1241-1252.

van Overveld, M., de Jong, P. J., \& Peters, M. L. (2009). Digestive and cardiovascular responses to core and animal-reminder disgust. Biological Psychology, 80, 149-157.

van Overveld, M., de Jong, P. J., \& Peters, M. (2010). The disgust propensity and sensitivity scale - revised: its predictive value for avoidance behavior. Personality and Individual Differences, 49, 706-711.

Wenzel, A., \& Holt, S. J. (2003). Validation of the Multidimensional Blood-Injury Phobia Inventory: evidence for a unitary construct. Journal of Psychopathology and Behavioral Assessment, 25, 203-211.

Wenzel, A., \& Sawchuk, C. N. (2004). Psychometric properties of the multidimensional blood/injury phobia inventory. The Behavior Therapist, 27, 10-15.

Yartz, A. R., \& Hawk, L. W., Jr. (2002). Addressing the specificity of affective startle modulation: fear versus disgust. Biological Psychology, 59, 55-68. 